\title{
Justice, Legitimacy and (Normative) Authority for Political Realists
}

\author{
Enzo Rossi
}

[Forthcoming in Critical Review of Social and International Political Philosophy, March 2012.]

\begin{abstract}
One of the main challenges faced by realists in political philosophy is that of offering an account of authority that is genuinely normative and yet does not consist of a moralistic application of general, abstract ethical principles to the practice of politics. Political moralists typically start by devising a conception of justice based on their pre-political moral commitments; authority would then be legitimate only if political power is exercised in accordance with justice. As an alternative to that dominant approach I put forward the idea that upturning the relationship between justice and legitimacy affords a normative notion of authority that does not depend on a pre-political account of morality, and thus avoids some serious problems faced by mainstream theories of justice. I then argue that the appropriate purpose of justice is simply to specify the implementation of an independently-grounded conception of legitimacy, which in turn rests on a context- and practice-sensitive understanding of the purpose of political power.
\end{abstract}

\section{Introductory}

0.1 Mainstream contemporary Anglo-American political philosophy tends to conceive of itself as a branch of applied ethics: the task of normative political theory would be that of guiding politics so as to promote or honour certain pre-political moral commitments. However in recent years - under the labels of 'political realism'1 or 'the realist critique of liberalism'-a

1 Not to be confused, of course, with the related but much more circumscribed realist tradition in international relations theory. 
radically different approach to political theory has begun to emerge and take the form of a recognisable if spontaneous current. 2 In a nutshell, realists contend that normative political theory should not try to silence, circumvent, contain, or ignore the non-moral forces that shape politics—all tendencies that realists ascribe to mainstream contemporary political philosophy. In other words, political philosophy should not try to prescribe behaviour that runs against the grain of the practice of real politics.

A standard story in support of that approach has to do with the critique of purportedly 'purely normative' political theory as (an at least potential) expression of ideology. As Raymond Geuss puts it, "ethics is usually dead politics: the hand of a victor in some past conflict reaching out to try to extend its grip to the present and the future." (2008: 42) Another-related and vaguely Hobbesian-line of realist critique says that moralist political philosophy is ill-suited to its subject matter: we need politics just because we disagree on ethics, so applied ethics-based political theory will not do.3

One of the main aims of this paper is to advance the realist critique in a way that relies less on general observations of that sort-however convincing they may be-and more on a direct engagement with the object of its critique. I would like to show how adopting a realist approach can help us in making progress in debates where moralist theories are at an impasse. 4 More specifically, I will argue that debates on justice can be moved beyond a conflict between irreconcilable assumptions or intuitions if we abandon the moralist idea that justice is the first question of political philosophy.5 Rather, legitimacy (as understood by realists) is the fundamental problem, and once a realist account of legitimacy is in place we will have a new angle from which to approach some seemingly intractable disagreements about justice.

2 The work of theorists as disparate as William Connolly, John Dunn, John Gray, Bonnie Honig, John Horton, Chantal Mouffe, Glen Newey, Mark Philp, Judith Shklar, and Bernard Williams is beginning to be seen as contributing to the development of a the realist literature. For an overview, see Sangiovanni (2009) and Galston (2010).

3 Cf. Newey (2001), Williams (2005), Rossi (2010). Rawlsians might object that the project of political liberalism is precisely that of overcoming disagreements about comprehensive conceptions of the good by relying on political ideas of the good. That response elicits at least two separate rejoinders. On the one hand, some realists (Sangiovanni 2008, Sleat 2010) have put forward an interpretation of Rawls' later work that highlights its more context- and practice-sensitive aspects; but it also seems fair to say that much of mainstream political philosophy has not followed in the footsteps of what some have seen as Rawls' departure from moralism (in fact that aspect has attracted much criticism from Rawls' own followers - cf., for example, Scheffler 1994). On the other hand, the political-comprehensive distinction has been subjected to a number of powerful criticisms (e.g. Gaus 1999), so simply pointing to it will not be enough to fend off the realist challenges.

4 This paper's main focus is simply the realist critique of mainstream political philosophy, rather than the formulation of an alternative first-order realist theory of justice. For a sense of what the latter might look like, Sangiovanni (2008) provides examples of how a broadly realist approach can help us making progress on a number of familiar questions such as the right to free speech and the justification of human rights in a global context.

$5 \quad$ The incipit of Rawls' A Theory of Justice (1999 [1971]) comes to mind here. I will return to it in 1.1 below. 
That argument also takes on a wider challenge faced by realists in political philosophy, namely that of offering an account of authority that goes beyond the notion of de facto authority-that is, and account which is genuinely normative and yet does not consist of a moralistic application of general, abstract ethical principles to the practice of politics. I would like to show that upturning the relationship between justice and legitimacy affords a normative notion of authority that does not depend on a pre-political account of morality. I argue that the appropriate purpose of justice is simply to specify the implementation of an independentlygrounded conception of legitimacy, which in turn rests on a context- and practice-sensitive understanding of the purpose of political power. Unlike mainstream approaches that take justice as their first question, by giving priority to (realist) legitimacy my proposed sequence makes it possible to specify the scope of application of our theory of justice in a freestanding way, allowing it to be genuinely normative and action-guiding, but also grounded in an adequate account of the sphere it is meant to regulate.

0.2 The paper is structured as follows. In section $1 \mathrm{I}$ characterise political moralism and argue that it fails to provide an adequate account of the scope of justice. In section 2 I show how that problem can be overcome through the priority of (realist) legitimacy over justice. In the third and final section I summarise my argument and briefly canvass some of the further questions it prompts.

\section{Rejecting Moralism}

1.1 The view that justice is the fundamental subject matter of political philosophy is closely connected to the moralistic approach to political philosophy, as I shall clarify shortly; so we begin with a thumbnail sketch of what I take to be the two ways in which mainstream political philosophy seeks to apply ethics to politics. 6

(i) Substantive/teleological approach: The idea here is to set out an account of the good, and then devise the right (i.e. justice) accordingly. The paradigmatic example of this approach is utilitarianism, whereby justice requires the implementation of the set of rules that maximises utility. The good is prior to the right on this approach, nonetheless the fundamental political-

6 Bernard Williams (2005: 3) puts forward a similar distinction between the 'enactment' and the 'structural' model of political philosophy. 
philosophical problems are still cashed out in terms of justice. The account of the good is presupposed and pre-political, so the role of political philosophy just is to work out a set of principles of right to maximise the good.

(ii) Procedural/deontological approach: The aim here is to specify the right independently of the good.7Rawls' theory of justice is perhaps the most familiar example of this approach: some prepolitical moral commitments are identified as constitutive of the concept of justice and are then formulated as a conception of justice through an appropriately specified procedure. Politicalphilosophical problems are then addressed by applying that conception.

As anticipated both approaches share the (moralistic) aspiration to guide political action on the basis of moral ideals (such as impartiality or well-being, say) that are external and prior to politics, in the sense that they are valued prior to and independently of any assessment of how suitable they are as organising principles for the regulation of political matters in any particular context. In fact Raymond Geuss calls this approach the 'ethics first' view (2008: 9), and Bernard Williams dubs it 'political moralism' (2005: 2). In a similar vein, Andrea Sangiovanni recently characterised the mainstream approach to justice as 'practice-independent':

In each case, the principle of entitlement, utility, equality or priority (and the currency in which it is specified), is justified by appealing solely to moral values or to facts about human beings as such. No reference is made to existing institutions or practices, and the content, scope and justification of such principles in no way depend on the underlying structure of functioning of such practices and institutions. (2008: 139-140)8

Now that characterisation may well raise some important issues to do with the relation between moralism, fact-(in)sensitivity and ideal theory;9 however those issues are not of direct concern here. Rather, our focus should remain on the point that both variants of mainstream political philosophy try to achieve the priority of ethics over politics by affording centrality and priority to the question of justice. On the substantive approach justice is the means by which the moral ideal is implemented. On the procedural approach the role of justice is even more central: to implement the guiding moral ideal just is to implement a conception of justice.10

\footnotetext{
$7 \quad$ Set aside the familiar question-which I have discussed in Rossi (2009)-of whether procedural accounts of justice need to rely on a substantive account of desirable outcomes. On this issue also see Ceva (2009 and 2012) and Newey (2012).

8 One may object that Rawls' notion of a realistic utopia is meant to anticipate precisely this sort of charge. Yet, arguably, Sangiovanni's notion of practice-dependence (to which I will return in 2.2 below) is more contextspecific and thus more demanding than Rawls' rather abstract concern with laws of nature, "persons' moral and psychological natures" and "general facts about human society" (1999: 119, 175).

$9 \quad$ See Cohen (2003) and, for a critical discussion, Guay (2009).

10 This discussion provisionally presupposes the viability of Rawls' distinction between the concept and the
} 
More precisely, my claim here is that moralism's reliance on pre-political moral commitments is a necessary and sufficient condition for the priority of justice. If we decide that the point of political philosophy is to specify how to implement some pre-political moral commitments, then we will think of our primary task as that of specifying a set of rules to bring about that implementation. Our conception of justice, then, is constituted by the specific rules we devise to implement our pre-political values.11 Consistently with the distinction between the two variants of moralism outlined above, those rules and values may then be teleological or deontological, as the priority of justice is separate from the priority of the right over the good. 12 But the need to translate pre-political moral commitments into first-order principles of justice only explains why moralism is a sufficient condition for the priority of justice. The stronger claim that it is also a necessary condition can be explained by pointing out how, if we want justice to be "the first virtue of social institutions" so that "laws and institutions no matter how efficient and well-arranged must be reformed or abolished if they are unjust" (Rawls 1971: 3), we need to draw on pre-political normative commitments exclusively: that categorical role can only be performed if justice is grounded in abstract moral ideals (or practice-independent in the sense seen above), lest our judgment be swayed by historically-situated political contingencies such as a particular society's track record with the implementation of constitutional changes, say. In other words, if justice is to be the fundamental test for whether a political system stands or falls from the normative point of view, on pain of circularity the principles guiding judgments of justice should not be shaped by the nature of their subject matter. However, as we will see in the next sub-section, this pratice-independence spells serious difficulties for either version of the moralistic approach.

1.2 Given the relationship between moralism and the priority of justice, even if the two general arguments against moralism mentioned in the introductory section (the critical theory one and the Hobbesian one, neither of which I discuss here) were to fail, if the priority of justice can be shown to have undesirable effects moralism would still be undermined. But what could be wrong with the priority of justice? My contention is that moralist accounts of justice generate intractable controversies because they are incomplete. In a nutshell, my argument is this.

conceptions of justice.

11 I will spell out this point I more detail in my discussion of the justice-legitimacy distinction in 2.1 below.

12 See Sandel (1998: 2-3): Not only Kant, but even J.S. Mill gives priority to justice, at least at the first order level (but, unlike Kant, not at the level of justification). 
The normative outcome of any theory of justice is partly determined by the scope of justice, but the scope of justice cannot be determined with reference to pre-political moral values. Since on the moralist approaches the salient content of any conception of justice is determined by prepolitical values, those conceptions cannot contain an account of their scope. Therefore the moralist approaches yield incompleteness about matters of justice, in the sense that disagreements between competing moralist conceptions of justice cannot be adjudicated purely within the conceptual space of those theories. So, crudely, my claim is that moralist theories of justice talk past each other in a crucial respect.

Consider, for example, the familiar contrast in distributive justice theory between liberal egalitarians and libertarians on the issue of taxation and redistribution. The dispute is usually carried out in terms of the implications of self-ownership, or the nature of the basic structure, and so on. Typically the dialectic reaches an impasse where some basic intuitions conflict, as there is no widely shared adjudication methodology for such conflicts. My conjecture here is that the indeterminacy of those disagreements is due to a lack of agreement about the scope of justice. The scope question is the question of where coercive political power should reach. In other words, it is the question of which part of 'the political' should be regulated by the sort of norms laid out by political philosophy. If we begin from the scope question we will have a common ground on which to debate justice; but I want to argue that no moralist theory of justice can contain an account of its scope and, therefore, justice (as understood by moralists) cannot be the first question of political philosophy. Moralists want to start from a conception of justice, yet those conceptions are constituted by non-political ethical principles applied to politics, whereas determining the scope of justice is a question about the nature of politics itself. So we need to start from a realist theory of legitimacy instead, i.e. a theory of what politics is actually for in a given context.

For instance, in the case of the libertarian/egalitarian dispute, an account of the scope of justice would go a long way towards settling the issue of whether certain individual entitlements are defeasible (at least in a given context). Whether the state can legitimately redistribute a percentage of private income for particular purposes would no longer be a matter of whether such an exercise of political power is compatible with respect or promotion of certain abstract pre-political moral commitments (autonomy, rights, etc.); on a legitimacy-driven realist approach the matter would be discussed as the partly empirical and hermeneutical issue of the meaning and purpose of politics in that particular context. And, as I will argue, that should provide a 
firmer basis for philosophical discussion than a clash of (allegedly) pre-political moral intuitions.

Before expounding the argument I just sketched it may be useful to lay out its bare structure:

P1: An account of the scope of justice is necessary (but not sufficient) to determine the normative outcome of any theory of justice. So the scope is part of the normatively salient content of a theory of justice.

P2: The normatively salient content of moralist conceptions of justice is entirely derived from pre-political moral values.

P3: An account of the scope of justice cannot be adequately provided with reference to pre-political moral values.

C1: Moralist conceptions of justice cannot adequately specify their scope. (From P1, P2, P3.)

C2: Moralist conceptions of justice are incomplete. (From P1, C1.)

First, what exactly is the scope of justice, and why does it matter to the normative outcome of a theory of justice? As we have seen, the scope of justice is the sphere that ought to be regulated by a theory of justice. Even if we simply maintained that the whole of 'the political' ought to be directly regulated by principles of justice we would need an account of why that should be the case. In Rawls' paradigmatic theory, the scope of justice is famously characterised through the idea of the basic structure of society (1999 [1971]: 6-10; 1993: 257ff.). Below I will argue that this characterisation is unsatisfactory due to Rawls' moralism; but first we need to see how the account of the scope affects the normative content of a theory of justice. To continue with the example of justice as fairness, the point is simply that the parties in the original position know that they are selecting principles for the basic structure; so, for instance, the content of (say) the difference principle is shaped by both a normative commitment to impartiality and the need to shape "the way in which the major social institutions distribute fundamental rights and duties and determine the division of advantage from social cooperation" (Ibid: 7). More generally, principles of justice are always implicitly formulated on the basis of an account of their scope insofar as ought implies can, and to know what is possible we need to know what sphere a norm is supposed to regulate (among other things).

The second premise of my argument is the claim that the normatively salient content of 
moralist conceptions of justice is entirely derived from pre-political moral values. Here the thought is simply that most contemporary political philosophers' prescriptions are entirely derived from or at least justified in terms of the articulation of a set of politics-independent moral values — as shown in the account of the deontological and teleological approach above. In other words, if we think of the formulation of principles of justice as an input-processingoutput operation, we may say that the input, or the raw material (as it were), is entirely constituted by those pre-political moral commitments. Again, consider Rawls' theory of justice as fairness (or at least its early formulation in the first edition of $A$ Theory of Justice).13 Moral intuitions on freedom, equality and impartiality are systematised through the method of reflective equilibrium, which in turn yields the normative commitments that inform the design of the original position. The resulting two principles of justice, then, are the result of a series of manipulations of those initial, pre-political moral commitments. The same is true of Robert Nozick's libertarianism, where entitlements are derived from an account of moral agency in a 'state of nature' (1974: 48ff), or of various versions of consequentialism (which are rooted in a general moral account of well-being or perfection, say).

We can now move on to the third premise, namely why an adequate account of the scope of justice cannot be provided with reference to pre-political moral commitments (such as impartiality, reciprocity etc.), which are, however, the only source of the salient content of moralistic theories of justice. So the argument for this premise is in two steps: first I need to show that even the account of the scope in moralist theories of justice is derived from prepolitical moral commitments, and then why that is not an adequate way of characterising the scope of justice. The first step may appear particularly controversial. To take the example of justice as fairness again, one may just observe how Rawls has a separate account of the basic structure as the domain of application of his theory. But I wish to argue that Rawls' basic structure is not a satisfactory account of the scope of justice, because the pre-political normative commitments that give rise to the original position and the ensuing principles of justice also inform the account of the basic structure: "once we think of the parties to a social contract as free and equal (and rational) moral persons, then there are strong reasons for taking the basic structure as the primary subject." (1993: 258-9). Put another way, even though the parties in the original position know that they have to work out principles of justice for the regulation of the

13 Since the 1980's Rawls has progressively been introducing contextual elements in his account of justice (on this point see Sangiovanni 2008), so his position has become increasingly less moralistic. However for our present purposes it will be necessary to focus on clear-cut cases of moralist approaches to justice. 
basic structure, the account of the basic structure is informed by a prior understanding of what counts as background justice:

We start with the basic structure and try to see how this structure itself should make the adjustments necessary to preserve background justice. [...] Certain background conditions are necessary if transactions between individuals are to be fair." (Ibid:: 268-9).14

That ethics-driven process is even more straightforward in the case of other moralistic theories of justice. As Rawls cogently argues, libertarian and utilitarian theories do not even have a special place for something akin to the basic structure, so they proceed directly from prepolitical moral commitments to political prescriptions, making no principled distinctions between moral and political norms (Ibid:: 262-5). Their account of the scope of justice, then, depends implicitly but entirely on their pre-political moral commitments: the account of the institutions to be regulated is just an implication of those commitments.

Now the second step of the argument for the third premise: what exactly is wrong with having an account of the scope of justice that depends on pre-political normative commitments? After all, while one may find fault with the way in which libertarianism and utilitarianism do not deal explicitly with the scope issue, Rawls' move may appear compelling, insofar as it explicitly specifies what institutions 15 we should regulate if we are committed to certain values.16 But my contention is that that move begs the question of whether regulating those institutions rather than others is actually a pressing political problem, or simply becomes one if one has certain prepolitical normative commitments. In other words, the problem is that moralist theories of justice do not really provide a freestanding account of their scope-they just spell out the implications of their pre-political normative commitments. And that is why they talk past each other: if the account of the scope is not grounded independently of the pre-political normative commitments, then we cannot have a debate on which principles are best suited to a given set of problems (despite the fact that debates are often framed in this way), and the substance of the disagreement is actually a clash between conflicting intuitions about the preferability of certain pre-political normative commitments over others.17

14 Set aside, for now, the issue of whether this need for a prior understanding of the notion of background justice makes the original position a somewhat circular decision procedure.

15 I use the word 'institutions' in a deliberately loose and wide-ranging way here. One may however note that, as Christopher Bertram (2009) has persuasively argued, much of the literature on the basic structure tends to blur two conceptions of that concept: a quasi-legal one, focused on rules and institutions, and a sociological one, focused on broader features of society. My argument should be able to range over that distinction.

16 However, if my analysis is correct, at a deeper level the account of the basic structure does not mark a significant structural difference between justice as fairness and libertarianism or utilitarianism.

17 Here one might object that some normative assumptions are needed to begin to identify the normatively 
The three premises I just defended should lead us to the conclusion that moralist conceptions of justice do not have the resources to provide an adequate account of their own scope. They will of course presuppose such an account (for the reasons seen when discussing the first premise), but it will not be adequate in so far as it will be dependent on pre-political moral commitments.

If we accept the first conclusion we should also accept the second one: moralist conceptions of justice are incomplete, in the sense that their normative outcomes are not adequately determined (because their account of the scope of justice is not freestanding). This objection may arguably be presented as a kind of circularity charge: moralistic theories of justice present their normative outcome as a solution to the problems raised by the application of their pre-political normative commitments to an account of the scope of justice, but that account is itself dependent on those normative commitments. So the problem is characterised in a way that is biased towards the envisaged solution.18 However, that may not be too serious a worry if there were no alternative way of formulating action-guiding principles for the exercise of political power; so in the reminder of this paper I shall attempt to show how a realist approach may overcome the difficulties I just pointed out.

\section{The Priority of Legitimacy}

2.1 To avoid the difficulty pointed out by my argument against the moralist priority of justice we need a freestanding account of the scope of justice, i.e. one that is not dependent on pre-political moral commitments. I argued that such an account cannot be provided within a theory of justice; in other words, the priority of justice is inescapably connected to moralism. That is why, as I will argue in this section, we need to move from moralism to realism, which involves taking legitimacy rather than justice as our first question.

Let me outline that move more thoroughly. Mainstream, moralist theories of justice begin from an account of what (pre-political) values should regulate the exercise of political power. They identify a set of relevant general moral commitments and proceed to apply them to

salient features of a political context, and so the moralistic way of construing the scope of justice is inevitable. I do not deny that; my reply would be simply to point out that, on the the moralist approach, all of the salient content of the scope is derived from pre-political moral commitments.

18 I will not discuss whether my argument should be considered fatal to the moralist approach to justice, as that judgment is best left to the reader; but I do hope to have at least shown that incompleteness is a serious shortcoming. 
politics, either in a substantive or in a procedural way. My argument in the previous section aimed to show that if the source material-as it were-of a normative political theory is entirely constituted by those pre-political moral commitments we cannot have an adequate account of the scope of justice. But of course we do need such an account, because any normative theory that aspires to be action-guiding needs an effective theory of justice. So the challenge is to devise an appropriate theorising sequence that yields a theory of justice only after we have secured an independent account of the scope of justice. As anticipated, my suggestion is to start from a realist account of legitimacy, i.e. an empirically informed account of what politics is for in a given context. That, in turn, should allow us to adequately specify the scope of justice. The basic thought here is that, since the scope of justice is the sphere that ought to be regulated by principles of justice but cannot itself be adequately individuated through the pre-political moral commitments that constitute the salient content of moralistic accounts of justice, we need to recast the issue of scope as one to do mainly with the practice of politics itself, rather than the values that we would like to inform that practice. In other words, the question of where political power can legitimately reach should precede that of what principles should guide its exercise (call this the priority of legitimacy thesis), and it should be answered-at least in part-through an empirically informed account of the meaning and purpose of politics in the relevant cultural and historical context (call this the realist thesis).

To clarify that point it may be useful to explore the (somewhat stipulative) 19 distinction between the concepts of justice and legitimacy I am employing here. The question of justice is the question of what principles, rules, or action-guiding norms should regulate the exercise of political power in a given polity.20 The question of legitimacy, on the other hand, concerns the purpose of the exercise of political power in a given polity. Crudely, justice tells us how to exercise political power, whereas legitimacy tells us what the exercise of political power is for-which should explain why I maintain that the latter should question be prior to the former. The two concepts are obviously related and it may even be possible to envisage conceptions of both that give them the same extension;21 but my point here is simply to show how it is possible to drive a conceptual wedge between the norms that should regulate political action (justice) and the

19 While a degree of stipulation is inevitable when dealing with contestable concepts such as justice and legitimacy, that should not pose serious problems here, insofar as my argument simply aims to show a sequence of steps that lead to adequately grounded action-guiding principles. What names we attach to those steps is not crucial. 20 Set aside the familiar questions of whether all political power is exercised by the state, or whether justice need only concern the political power exercised by the state, and so on (Cf. Cohen 2011: 227) - my argument is general enough to range over the various possible answers to those questions.

21 If, for instance, we maintained that a state is legitimate if and only if it is just. 
considerations that inform that choice of norms (legitimacy). In other words, legitimacy concerns the question of why we need politics in the first place, whereas justice concerns the rules through which politics should be regulated.

Now that characterisation of the justice-legitimacy distinction should point us towards the way in which giving priority to a realist account of legitimacy can solve the problem with the scope of justice I described in the previous section (1.2). Recall how the moralistic priority of justice cannot yield a freestanding account of the scope of justice, i.e. of the limits of the sphere of action to be regulated by a conception of justice. In light of my argument we may say that, on the moralist approach, the difficulty with scope appears two-pronged. On the one hand the priority of justice aspires to spell out action-guiding norms before specifying the purpose of those norms. On the other hand, drawing the account of the scope of justice from pre-political moral commitments fails to ensure that the scope encompasses genuine political concerns, rather than what counts as a political concern in light of certain pre-political moral commitments. So the two prongs are really the two sides of the same coin:22 pre-political normative commitments cannot yield an adequate account of the scope of justice because they are geared towards generating general action-guiding principles, not an account of the purposes of politics in a given context. And it would not be possible to start from purpose-oriented pre-political commitments because we have seen (in 1.1 above) how moralism requires the priority of justice, and vice versa. That is why I maintain that the difficulty posed by the scope problem can only be overcome by starting our sequence of normative theorising from a realist account of legitimacy: we need to start from an account of the deep purpose of the exercise of political power (i.e. of legitimacy), which justice (as defined above) cannot provide, and since that account cannot be grounded on pre-political moral commitments we need it to be empirically informed (i.e. realist). 23

But how can we generate such an account of legitimacy, and does it yield genuinely normative and action-guiding notions of political authority and justice? In the next sub-section I will sketch the general structure of a realist theory of legitimacy, and the way in which an adequate account of the scope of justice (and so an action-guiding conception of justice) can

22 That is unsurprising, as in 1.1 we saw that the relationship between the priority of justice and moralism is a biconditional.

23 In discussing the need for the empirical grounding of a realist conception of legitimacy both Williams (2005: 9) and Geuss (2008: 34-36) refer to the exemplar of Weber's seminal work, which, regrettably, has been largely neglected by post-Rawlsian political philosophy. Relatedly, until the last few years David Beetham (1991) has been a relatively lone voice in putting forward the view that the normative and descriptive aspects of legitimacy cannot be disentangled. I will return to this general issue in 2.2 below. 
emerge from it.

2.2 One may ask in what sense, exactly, a realist account of legitimacy should be empirically informed, and what that implies with regard to the way in which the role of normative political theory is traditionally conceived. My suggestion would be to move beyond gesturing at a vaguely Weberian notion of legitimacy,24 and answer both questions by drawing on Andrea Sangiovanni's (2008) account of practice-dependence in normative political theory. More specifically, while Sangiovanni puts forward a theory of practice-dependent justice, I would like to show how, in light of my argument against the priority of justice, the realist cause of practice-dependence is best served by a focus on legitimacy. That is not to say, of course, that there is no role for justice; my contention is simply that a realist and practice-dependent account of justice cannot stand alone or be our first question - it should rather descend from an account of legitimacy.

Sangiovanni's practice-dependent account of justice explicitly incorporates many insights from the realist critique of mainstream political philosophy. 25 Most importantly for our present purposes, it offers a hermeneutic approach to the articulation of the empirical component of any realist approach to normative political theory:

The content, scope, and justification of a conception of justice depends on the structure and form of the practices that the conception is intended to govern. [Therefore] in justifying any conception of justice, we first need an interpretation both of the point and purpose of the institutions that the conception is intended to govern, and of the role principles are intended to play within them. (Ibid.: 138, 141, my italics)

I will not rehearse Sangiovanni's argument for practice-dependence,26 as my argument from the scope of justice should already have established the case for realism. What I do wish to establish now, however, is that the argument from the scope of justice should also lead us to a form of realism that proceeds from a practice-dependent account of justice to an action-guiding account of justice, rather than yielding a freestanding conception of justice. Simplifying somewhat, Sangiovanni maintains that the existence of institutional systems gives rise to peculiar relations between persons, and those relations in turn generate a demand for regulation through a conception of justice. The way to devise such a conception, then, is to interpret the purpose of $24 \quad$ See previous footnote.

25 In fact Sangiovanni points out the close connections between his views and those of Williams, Geuss, and even Weber and Morgenthau (2008: 158n, 163n).

26 Nor, more specifically, his argument for the particular form of practice-dependence he favours, namely one focused on institutional rather than cultural practices. 
those institutions in a way that is sufficiently critically aware to generate a normative assessment of existing arrangements as well as action-guiding principles of justice. But Sangiovanni recognises a potential difficulty with that move:

We may be worried that in interpreting an institutional system in this way, we must apply standards of value that we already endorse independently of the institutions we are considering. Without such initial assessment of value, we will not be able to make sense of the point and purpose of a practice or activity $[\ldots]$ And this may seem to make the interpretive step in the justification of a conception of justice viciously circular. (Ibid.: 149)

To address that worry Sangiovanni points out that the interpretation of existing practices is only an initial and provisional step. The conception of justice cannot be entirely derived from the interpretive understanding of institutions; that understanding must be 'extended' into a further, critical stage. While "without the constraints provided by the interpretive step, justice [...] would have neither a determinate content nor an application", taking those constraints into account is not sufficient to derive a conception of justice. To complete the critical stage, then, we need to "move from the point and purpose of institutions and the reasons those involved have for affirming them, to the way they shape relations among participants" (ibid.: 150). Presumably those relations are to be critically assessed by the lights of freestanding, perhaps even prepolitical normative commitments that are able to yield action-guiding principles. 27

So it would appear that, by delaying the introduction of those normative commitments until after the interpretation of the point and purpose of the relevant institutions, Sangiovanni has managed to avoid the moralistic pitfall of characterising the scope of justice through the distorting lens of abstract, pre-political moral values. However, if we pay closer attention to the interpretive stage we should come to realise that, while Sangiovanni may well have dispelled the circularity worry in the terms in which he formulated it, my account of the problem of the scope of justice could be recast it in a more insidious way. The problem is that Sangiovanni's interpretive process is geared towards picking out the features of institutions that are relevant to some prior notion of justice: "the aim of the interpretive stage is to establish the parameters and fixed points which a full-blown conception of justice must take into account. [It] is meant to provide structure to the justification of a conception of justice" (ibid.: 149). Interpreting a practice through the lens of a concept of justice cannot yield a freestanding account of the scope of justice, i.e. the sphere of action that ought to be regulated by normative political theory.

$27 \quad$ Sangiovanni clarifies this point through an interpretation of Rawls' theory of justice as fairness in its later recasting as well as through a discussion of a number of aspects of recent debates on global justice (ibid.: 150-6). I take those illustrations to be successful, so I will not provide examples here. 
In other words, how do we know (without projecting our own pre-political normative commitments, that is) whether a certain practice is meant to contribute to the establishment of justice? It seems to me that, in looking for justice at the interpretive stage, Sangiovanni skipped a step of the sequence required by a genuinely realistic mode of normative theorising. As anticipated, my suggestion would be to postpone the search for justice until we have an account of legitimacy; so, if the interpretive stage is to genuinely explore the 'point and purpose' of institutions, it should rather focus on drawing out an account of legitimacy. 28 That is because, unlike justice, legitimacy is actually about the purpose of the exercise of political power, 29 so using it as a hermeneutic lens will not cause any distortion, as it were. Such a genuinely freestanding account of the purposes of politics in a given context will then yield an adequate account of the scope of justice, and on that basis, as envisaged in Sangiovanni's critical stage of realist theorising, we will of course be able to devise suitably action-guiding principles of justice.

\section{Conclusion}

3.1 Let us now briefly review the paper's argument. I started by identifying a tendency, in mainstream contemporary political philosophy, to generate action-guiding principles whose salient content is drawn entirely from pre-political moral commitments. This moralistic tendency is strictly tied to the idea that justice is the first question of political philosophy. I then argued that, however, the moralistic approach yields inadequate theories of justice, insofar as it is unable to provide a freestanding account of the scope of justice, i.e. of the boundaries of the sphere of the exercise of political power that ought to be regulated by principles of justice. To overcome that difficulty I proposed to give priority to the question of legitimacy over justice, understanding the former in an empirically informed, realist way. I then showed how a realist account of legitimacy can generate a practice-dependent but genuinely normative conception of justice. In that way the realist approach to political philosophy can move beyond the notion of mere de facto authority and carve some space for a critical and action-guiding alternative to mainstream political moralism.

To be sure, my argument points to a number of open questions. Tackling them in any detail,

28 So we may say that Sangiovanni's practice-dependence yields a contextualist position about justice. But I maintain that contextualism is not enough of a departure from moralism to overcome the problem of the scope of justice; for that we need the priority of legitimacy, which yields a full-blown realist position (as contextualism is just a component of realism).

29 See 2.1 above. 
or even listing them, would be beyond the scope of this paper; yet, in order to sketch a possible direction for the realist research programme, it may be helpful to mention what may well be the most pressing worry, namely whether practice-dependence does not place excessive constraints upon the sort of prescriptions that a theory may envisage-however the realist may well point out that a solid grounding in a context's factual constraints is the best platform on which to construct radical alternatives.30 The challenge, then, becomes that of tackling the descriptive and hermeneutic element of political theory in a way that is sufficiently critically aware to pave the way for realistic normative solutions. 31

\section{References}

Beetham, D., 1991. The Legitimation of Power. Basingstoke: Palgrave Macmillan.

Bertram, C., 2010. Institutions and the Limits of Procedural Justice. Unpublished manuscript, Department of Philosophy, University of Bristol.

Ceva, E., 2009. Just Procedures with Controversial Outcomes: On the Grounds for Substantive Disputation within a Procedural Theory of Justice. Res Publica, 15(3), 219-235.

Ceva, E. 2012. Beyond Legitimacy: Can Proceduralism Say Anything Relevant about Justice? Forthcoming in Critical Review of International Social and Political Philosopby.

Cohen, G.A., 2003. Facts and Principles. Philosophy \& Public Affairs, 31(3), 211-245.

Cohen, G.A., 2011. How to Do Political Philosophy. In On the Currency of Egalitarian Justice and Other Essays in Political Philosophy, 225-235. Princeton, NJ: Princeton University Press.

Galston, W.A., 2007. Realism in Political Theory. European Journal of Political Theory, 9(4), 385-411. Gaus, G.F., 1999. Reasonable Pluralism and the Domain of the Political: How the Weaknesses of John Rawls's Political Liberalism Can be Overcome by a Justificatory Liberalism. Inquiry 42(2), 259-284.

Geuss, R., 2008. Philosophy and Real Politics, Princeton: Princeton University Press.

Geuss, R., 2010. Politics and the Imagination, Princeton: Princeton University Press.

Guay, R., 2009. On Being Constrained by the Facts: Cohen on Facts and Principles. Unpublished manuscript, Department of Philosophy, SUNY Binghampton.

$30 \quad$ See Geuss (2010: $\mathrm{x}$-xi).

31 Various versions of this paper were presented at Central European University, Bayreuth University, the University of Wales, Newport, and Warwick University - I am grateful to all audiences for their feedback. I would also like to thank Emanuela Ceva, Chandran Kukathas, Richard North and Janosch Prinz for their helpful written comments. 
Newey, G., 2001. After Politics, London: Palgrave Macmillan.

Newey, G., 2012. Just Politics. Forthcoming in Critical Review of International Social and Political Philosophy.

Rawls, J., 1999 [1971]. A Theory of Justice. Cambridge, MA: Belknap.

Rawls, J., 1999. The Law of Peoples: With 'The Idea of Public Reason Revisited'. Cambridge, MA: Harvard University Press.

Rossi, E. 2009. The Exemption That Confirms the Rule: Reflections on Proceduralism and the UK Hybrid Embryos Controversy, Res Publica 15(3), 237-50

Rossi, E. 2010. Reality and Imagination in Political Theory and Practice: On Raymond Geuss' Realism. European Journal of Political Theory, 9(4), 204-212

Sandel, M., 1998. Liberalism and the Limits of Justice. 2nd ed. Cambridge: Cambridge University Press.

Sangiovanni, A., 2008. Justice and the Priority of Politics to Morality. Journal of Political Philosophy, 16(2), 137-164.

Sangiovanni, A. 2009. Normative Political Theory: A Flight from Reality? In Political Thought and International Relations, ed. Duncan Bell, 219-239. Oxford: Oxford University Press.

Scheffler, S., 1994. The Appeal of Political Liberalism. Ethics 105(1), 4-22.

Sleat, M., 2010. Bernard Williams and the Possibility of a Realist Political Theory. European Journal of Political Theory 9(4), 485-503.

Williams, B., 2005. Realism and Moralism in Political Theory. In In the Beginning Was the Deed. Princeton: Princeton University Press, pp. 1-17. 